\title{
A VUELTAS CON LA FUNCIÓN POLÍTICO-CRIMINAL DEL BIEN JURÍDICO
}

\author{
Marta Fernández Cabrera \\ Área de Derecho Penal \\ Departamento de Derecho Público \\ Facultad de Derecho \\ Universidad de Málaga \\ martafc@uma.es
}

\begin{abstract}
RESUMEN
El bien jurídico es para la mayoría de los penalistas la piedra angular de la teoría jurídica del delito y un instrumento que cumple importantes funciones dogmáticas y politico-criminales. A pesar de ello, su función politico criminal, aquella que sirve de límite al legislador en su tarea criminalizadora, está siendo seriamente cuestionada. Los argumentos utilizados por los denominados «detractores del bien jurídico» se apoyan en que no está funcionando como verdadero límite al fenómeno de expansión penal. El legislador crea cada vez más tipos delictivos, amplía otros ya existentes o protege realidades poco precisas o de dudosa esencialidad para la convivencia social. Por ello, bay quien considera que se trata de una teoría obsoleta que no es capaz de enfrentarse con éxito a los problemas político-criminales actuales. Sin embargo, a lo largo de las siguientes líneas se pondrá de manifiesto que la supuesta crisis de la función crítica del bien jurídico obedece, entre otros motivos, a concepciones erróneas del mismo o de su lesión que lo vacian de contenido y le impiden llevar a cabo dicha función.

Palabras clave: bien jurídico, principio de exclusiva protección de bienes jurídicos, función político-criminal del bien jurídico, principio de lesividad.
\end{abstract}

\section{ABSTRACT}

Legal goods are for most penal law scholars the cornerstone of the legal theory of crime as well as a tool with core dogmatic and political-criminal purposes. However, their political criminal purpose, which serves as a limit to the ruler in their job as a criminaliser, is being seriously questioned. The reasons used by the so-called «legal goods oppositors» are based on such not being a truly limit to penal law expansion. The ruler creates more and more criminal types, widens others already in force or protects unclear realities or those which are doubtedly essential to the purpose of social cohabitation. Thus, some might say that it is all about an obsolete theory incapable of successfully facing current political criminal issues. However, throughout the following lines we will claim that the so-called crisis of legal goods is due to, among other reasons, a misconception of the latter or of its abuse which empty it from its content and do not let it meet its purpose.

Keywords: Legal goods, principle of exclusive protection of legal goods, political criminal purpose of legal goods, principle of harmfulness. 


\section{ZUSAMMENFASSUNG}

Das Rechtsgut ist für die meisten Strafrechtler der Eckpfeiler der Straftatstheorie und ein Instrument, das wichtige Lehr- und strafrechtliche Funktionen erfüllt. Jedoch wird die politisch-strafrechtliche Funktion, die dem Gesetzgeber seine Grenze bei der Strafgesetzgebung weisst, ernstlich in Frage gestellt. Die verwendeten Argumente von den sogenannten »Rechtsgutkritikern" stützen sich darauf, dass dieses Rechtsgut keine wirkliche Grenze mehr darstellt bezüglich des Phänomens der Ausdehnung des Strafrechts. Der Gesetzgeber erschafft immer mehr Straftatbestände, erweitert bestehende oder schützt wenig konkrete Wirklichkeiten oder von zweifelhaftem Wesen bezüglich des sozialen Zusammenlebens. Daher gibt es Einige, die annebmen, es handele sich um eine obsolete Theorie, die nicht in der Lage ist, sich erfolgreich den aktuellen politisch-strafrechtlichen Problemen zu stellen. Andererseits soll im folgenden Essay gezeigt werden, dass die sogenannte Krise der kritischen Funktion des Rechtsguts unter anderem darauf berubt, dass irtümliche konzeptuelle Vorstellungen desselben oder von seiner Verletzung vorberrschen und dazu führen, dass der Begriff entleert wird wodurch er seine Funktion nicht mebr ausüben kann.

Schlüsselwörter: Rechtsgut, Prinzip des ausschließlichen Schutzes der Rechtsgüter, politisch-strafrechtliche Funktion des Rechtsguts, Prinzip der Rechtswidrigkeit.

\section{SUMARIO: I. INTRODUCCIÓN.-II. CARACTERÍSTICAS DEL BIEN JURÍDICO Y DE SU LESIÓN EN UN DERECHO PENAL MATERIAL.-1. Objeto concreto dela realidad social.-2. Carácter lesionable a través de acciones individuales.-3. Sólo intereses fundamentales para la convivencia social externa.-III. FUNCIÓN POLÍ- TICO-CRIMINAL LIMITADA.-IV. CONCLUSIÓN.-V. BIBLIOGRAFÍA.}

\section{INTRODUCCIÓN}

Discutir en torno a la idea de bien jurídico y sobre la teoría de exclusiva protección de los mismos resulta ineludible para todo penalista en algún momento de su carrera. La importancia de este elemento para los países de tradición continental se pone de manifiesto con la posición que ocupa la discusión en torno al mismo en los trabajos de parte especial, siendo el primer paso del penalista llevar a cabo como mínimo unas nociones básicas. Sin embargo, a pesar de su importancia, se trata de un elemento que no adopta una concepción unitaria para toda la doctrina y que en la actualidad se encuentra atravesando una profunda crisis.

Al bien jurídico le son reconocidas generalmente ciertas funciones dogmáticas, como las de servir de criterio de sistematización e interpretación de los tipos penales ${ }^{1}$. Pero también se le asigna una función políti-

${ }^{1}$ Detallan las funciones dogmáticas que ejerce este elemento K. AmELUnG, «El concepto "bien jurídico" en la teoría de la protección penal de bienes jurídicos», en R. HEFENDEHL 
co-criminal de crítica al legislador penal en su tarea criminalizadora. Las funciones dogmáticas son enumeradas más o menos extensamente por los autores, pero raramente son cuestionadas, donde se sitúa la polémica es en la función de límite al ius puniendi. Por ello, ciertas afirmaciones como «para ser legítimo todo precepto penal ha de proteger un bien jurídico» o «el derecho penal sólo ha de contemplar ataques contra bienes jurídicos» ${ }^{2}$, consideradas clásicas en nuestra materia, no deben ser aceptadas sin reflexionar, porque en la actualidad están siendo más cuestionadas que nunca. Al igual que sucediera entre causalistas y finalistas, el debate ha llegado hasta el extremo en que los dogmáticos se hayan divididos entre «defensores»y «detractores» del bien jurídico como instrumento de contención penal ${ }^{3}$.

A pesar de que la polémica en torno al mismo no es reciente, sino que se remonta incluso al origen del propio concepto, resurge con fuerza cada cierto tiempo y en la actualidad se ha visto relanzada con las aportaciones de diversos autores muy cualificados que han encontrado argumentos nuevos en contra de reconocerle a dicho instrumento funciones político-criminales ${ }^{4}$. Ahora bien, que no se trate de una cuestión reciente no significa

(ed.), La teoría del bien jurídico. ¿Fundamento de legitimación del Derecho penal o juego de abalorios dogmático?, Barcelona-Madrid, Marcial Pons, 2007, pp. 228- 233, y J. A. LASCURAín, «Bien jurídico y objeto protegible», Anuario de Derecho penal y ciencias penales, t. 60, núm. 1 (2007), pp. 119-163, esp. pp. 129-133.

2 J. L. Díez Ripollés, Derecho penal español. Parte general en esquemas, 4. ${ }^{a}$ ed., Valencia, Tirant lo Blanch, 2015, p. 24; C. Roxin, Strafrecht. Allgemeiner Teil, Band. 1, 4. ${ }^{\text {a }}$ ed., München, C. H. Beck, 2006, pp. 43-44; W. HASSEMER, «¿Puede haber delitos que no afecten a un bien jurídico penal?», en R. HeFENDEHL (ed.), La teoría del bien jurídico. ¿Fundamento de legitimación del Derecho penal o juego de abalorios dogmático?, Barcelona-Madrid, Marcial Pons, 2007, p. 97; J. M. SiLVA SÁnCHEZ, Aproximación al Derecho penal contemporáneo, Barcelona, Bosch, 1992, p. 267, y S. MIR PUIG, «Límites del normativismo en Derecho penal», Revista electrónica de ciencia penal y criminología, núm. 7-18 (2005), p. 13, disponible bttp://criminet. ugr.es/recpc/07/recpc07-18.pdf. Como pone de manifiesto Hörnle: «No hay muchas afirmaciones en la ciencia penal alemana que se acepten de forma casi general. Sin embargo, sigue siendo típico que los trabajos penales sobre el sentido y fin del Derecho penal empiecen con el postulado de que las normas del Derecho penal sólo deberían servir para proteger bienes jurídicos» [T. HÖRNLE, «La protección de sentimientos en el STGB», en R. HEFENDEHL (ed.), La teoría del bien jurídico. ¿Fundamento de legitimación del Derecho penal o juego de abalorios dogmático?, Barcelona-Madrid, Marcial Pons, 2007, p. 382].

3 Sobre el estado de la discusión actual vid. R. HeFEndeHL (ed.), La teoría del bien jurídico. ¿Fundamento de legitimación del Derecho penal o juego de abalorios dogmático?, Barcelona-Madrid, Marcial Pons, 2007, p. 20, y B. J. FeIJoo SÁnCHEZ, «Sobre la crisis del bien jurídico. Recensión a R. Hefendehl (ed.): La teoría del bien jurídico. ¿Fundamento de legitimación del Derecho penal o juego de abalorios dogmático?», Indret, núm. 2 (2008).

${ }^{4}$ Tampoco consideran que nos encontremos ante un debate actual M. Alonso Álamo, «Bien jurídico material y bien jurídico procedimental y discursivo», en J. C. CARBONELL 
que se encuentre en un callejón sin salida o que nos avoque a una discusión doctrinal inerte. El debate sobre el bien jurídico apunta a los propios fundamentos del Derecho penal y resulta especialmente necesario en la actualidad dadas las dimensiones que ha adquirido este sector del ordenamiento. Por ello, es imprescindible averiguar si efectivamente nos encontramos con un instrumento con capacidad de llevar a cabo una crítica a la legislación penal o, por el contrario, debemos desecharlo en pro de otros principios más útiles.

Los argumentos utilizados por el grupo de los denominados «detractores» son variados, pero el desencanto con respecto al mismo proviene fundamentalmente del hecho de que no haya funcionado como un verdadero límite al fenómeno de expansión legislativa iniciado por el legislador penal en los países de tradición jurídica continental donde éste opera. En nuestro Códigos Penales se incorporan cada vez más tipos delictivos cuyos bienes jurídicos pueden suscitar enormes dudas sobre su importancia para ser considerados objeto de protección por este sector del ordenamiento (se amplían figuras delictivas ya existentes, se incrementa la punición de los actos preparatorios, se amplían los delitos de peligro...); fenómeno contra el que no está operando eficazmente.

Para algunos, esta incapacidad va asociada al propio concepto de bien jurídico y se trata de una incapacidad crónica, pasada y presente. Sin embargo, otros, aunque le reconocen una cierta aptitud crítica, consideran que no es eficaz frente a los problemas político-criminales modernos. Esto se debe, según Frisch, a que «los partidarios de un Derecho penal limitado a la protección de bienes jurídicos ya han visto cumplidas buena parte de sus exigencias» ${ }^{5}$. Así, desaparecidos del Código Penal la mayoría de delitos moralizantes (como la sodomía, el adulterio, la blasfemia...), la función crítica del bien jurídico raramente despliega en los ordenamientos

Mateu, J. L. González Cussac y E. Orts Berenguer (dirs.), y M. L. Cuerda Arnau (coord.), Constitución, derechos fundamentales y sistema penal (semblanzas y estudios con motivo del setenta aniversario del profesor Tomás Salvador Vives Antón), vol. 1, Valencia, Tirant lo Blanch, 2009, pp. 91-122; J. A. Lascuraín, «Bien jurídico y objeto...», op. cit., p. 125; R. Alcácer GuiraO, ¿Lesión de bien jurídico o lesión de deber? Apuntes sobre el concepto material del delito, Barcelona, Atelier, 2003, p. 21; S. Mir PuIG, «Bien jurídico y bien jurídicopenal como límites del ius puniendi», Estudios penales y criminológicos, núm. 14 (1989-1990), pp. 203-216, esp. p. 206, y J. Bustos RAmírez, Control social y sistema penal, Barcelona, PPU, 1987, esp. p. 186.

5 W. FRISCH, «Bien jurídico, derecho, estructura del delito e imputación en el contexto de la legitimación de la pena estatal», en R. HeFENDEHL (ed.), La teoría del bien jurídico. ¿Fundamento de legitimación del Derecho penal o juego de abalorios dogmático?, BarcelonaMadrid, Marcial Pons, 2007, p. 310. 
europeos una labor crítica tan activa como la que ejerció durante los años setenta y ochenta. Por ello, tan sólo se suelen enumerar como logros indiscutidos de esta teoría unos pocos casos emblemáticos, como la punibilidad de las conductas homosexuales llevadas a cabo por adultos o el castigo del incesto expuestos por Roxin ${ }^{6}$.

Sin embargo, que el bien jurídico pueda o no ejercer una función político-criminal depende de la concepción que del mismo se mantenga ${ }^{7}$. Que no la esté ejerciendo en este momento no implica su absoluta incapacidad para llevar a cabo dicha función, sino que puede indicar la falta de desarrollo de un concepto que le permita cumplir tal misión ${ }^{8}$. Este instrumento no puede ejercer ninguna función político-criminal, sino sólo funciones interpretativas y de clasificación de los tipos penales en aquellas concepciones doctrinales que lo hacen depender de lo establecido por el legislador en la ley, optando así por una concepción formal del delito 9 . Por el contrario, aquellos que consideran que el bien jurídico no es creado por el legislador, sino que, una vez trasladado a la ley penal, éste adquiere entidad propia y depende de aquello considerado fundamental para la convivencia social externa, optan por una concepción de bien jurídico capaz de llevar a cabo una crítica al ius puniendi y respetuoso con los postulados de un derecho penal material ${ }^{10}$. Dicho esto, correctamente

${ }^{6}$ C. Roxin, Strafrecht..., op. cit., pp. 7-50, e ÍD., «El concepto de bien jurídico como instrumento de crítica legislativa sometido a examen», Revista electrónica de ciencia penal y criminología, núm. 15 (2013).

7 S. Mir Puig, Introducción a las bases del Derecho penal, Barcelona, Bosch, 1976, pp. 131-132; J. M. Silva SÁnchez, Aproximación al Derecho penal..., op. cit., p. 267; P. R. Laurenzo Copello, «Recensión a J. M. Silva Sánchez, La expansión del Derecho penal. Aspectos de la política criminal en las sociedades postindustriales, 2. ${ }^{a}$ ed., Madrid, Civitas, 2001», Revista de Derecho penal y criminología, 2. ${ }^{a}$ época, núm. 12 (2003), p. 449; J. L. DíEZ RIPOLLÉs, «La contextualización del bien jurídico protegido», en J. L. DíEZ RIPOLLÉs, Estudios penales y de politica criminal, Lima, Idemsa, 2007, p. 35; J. TerRAdillos Basoco, «La satisfacción de necesidades como criterio de determinación del objeto de tutela jurídicopenal», Revista de la Facultad de Derecho de la Universidad Complutense, núm. 63 (1981), p. 124, y J. Bustos Ramírez, Manual de Derecho Penal. Parte General, corregida por H. Hormazábal Malarée, Barcelona, PPU, 1994, pp. 119-121.

8 S. Mir Puig, Introducción a las bases..., op. cit., p. 132.

9 Nos avoca a un derecho penal formal la propuesta de Jakobs de erigir como bien jurídico las expectativas normativas, dado que no limita cuáles son las que legítimamente pueden ser protegidas por el Derecho penal. Vid. G. JAKOBS, «¿Qué protege el Derecho penal: bienes jurídicos o la vigencia de la norma?», Cuadernos de doctrina y jurisprudencia penal, vol. VII, núm. 11 (2001), pp. 23-42. Pero también todas aquellas posiciones doctrinales que lo configuran como un elemento dependiente de lo establecido en la ley por el legislador, como, por ejemplo, U. KIndHÄusER, Strafrecht Allgemeiner Teil, 6. a ed., Berlin, Nomos, 2013, p. 36.

${ }_{10}$ Para la mayor parte de la doctrina, la dañosidad social es un concepto de referencia respecto al bien jurídico. Vid. S. MIR PUIG, Introducción a las bases..., op. cit., p. 132; 
configurado, el bien jurídico se encuentra íntimamente vinculado al concepto material de delito.

En un derecho penal material para la imposición legítima de un castigo penal no es suficiente con la mera infracción de una norma jurídico-positiva, sino que se deben exigir una serie de cualidades en cuanto al contenido de la acción punible ${ }^{11}$. Debe producir un efecto constatable en el mundo real que pueda calificarse de perjudicial para la convivencia social externa ${ }^{12}$. Es decir, exige la producción de determinados niveles de dañosidad social o lesividad. Constatada la existencia de dos concepciones del Derecho penal, una formal y otra material, la pregunta que se plantea como lógica a continuación es qué tipo de Derecho penal es preferible. Y lo cierto es que la misma no puede ser respondida en abstracto. Si queremos que la solución constituya algo más que una declaración de principios o una opinión personal habrá que acotarla sociotemporalmente y hacerla depender del sistema sociopolítico desde el que se aborda ${ }^{13}$. Así, según el art. 1.1 de la Constitución española, el Estado se constituye en un Estado social y democrático de Derecho que propugna como valores superiores de su ordenamiento la libertad, la justicia, la igualdad y el pluralismo político, y es desde este marco político desde donde deberá ser respondida. Por otra parte, en su art. 10 propugna el derecho fundamental a la dignidad humana, que en su relación con el derecho fundamental a la libertad implica que la actuación de los ciudadanos no será obstaculizada por el poder —el cual surge del propio pueblo, según el propio

J. Terradillos Basoco, «La satisfacción de necesidades...», op. cit., p. 134, y M. A. Abanto VÁsqueZ, «Acerca de la teoría de bienes jurídicos», Revista Penal, núm. 18 (2006), p. 4. En sentido contrario, Martín Pardo considera que se trata de un concepto autónomo y previo a la identificación del bien jurídico. Vid. A. MARTín PARDO, El bien jurídico protegido en los delitos urbanísticos, tesis doctoral, Málaga, Facultad de Derecho de la Universidad de Málaga, 2015, p. 428.

${ }^{11}$ C. Roxin, Strafrecht..., op. cit., p. 14.

12 Artífice de esta corriente de pensamiento es Amelung, que considera que el delito debe producir consecuencias sociales negativas en el sistema en que éste se lleva a cabo. Hasta ese momento, según este autor, se han descrito los efectos que produce el delito desde un punto de vista ideal o naturalista sin tener en cuenta a la sociedad. Por ello propone describir la dañosidad social como una perturbación de la convivencia social externa adoptando una concepción sistémica de la sociedad. Vid. K. AmELUng, Rechtsgüterschutz und Schutz der Gesellschaft, Frankfurt am Main, Athenäum, 1972, p. 388.

${ }^{13} \mathrm{~J}$. TerRadillos Basoco, «La satisfacción de necesidades...», op. cit., p. 141. En igual sentido, Seher pone de manifiesto que en el concepto de bien jurídico subyace el debate sobre el alcance legítimo del derecho penal. Vid. G. SEHER, «La legitimación de normas penales basadas en principios y el concepto de bien jurídico», en R. HeFEndeHL (ed.), La teoría del bien jurídico. ¿Fundamento de legitimación del Derecho penal o juego de abalorios dogmático?, Barcelona-Madrid, Marcial Pons, 2007, p. 77. 
art. 1.2 CE—. Todo ello conduce a que la libertad de actuación de los ciudadanos puede limitarse legítimamente a través de la imposición de una pena si existe una buena razón favorecedora de la convivencia social ${ }^{14}$. Por tanto, una intervención estatal que restrinja derechos fundamentales solo será legítima cuando exista una buena razón favorecedora de la convivencia social, que sólo será predicable cuando cuestione intereses directa o indirectamente fundamentales para los ciudadanos, es decir, cuando lesione un bien jurídico ${ }^{15}$. Por tanto, un tipo penal que no proteja un bien jurídico devendrá constitucionalmente ilegítimo porque, como dice Hassemer, «sería terror de Estado» ${ }^{16}$.

El propio Tribunal Constitucional español también se ha pronunciado en sentido similar exigiendo para la intervención del Derecho penal en una materia que «se realice con la finalidad de dotar de la necesaria protección a valores, bienes o intereses que sean constitucionalmente legítimos en un Estado social y democrático de Derecho» ${ }^{17}$. Así, la existencia de un objeto de protección penal legítimo es, según dicho Tribunal, el primer elemento lógico del principio de proporcionalidad, un prius lógico en la aplicación de dicho principio ${ }^{18}$. Por tanto, constituye «el primer material bruto para la discusión en torno a la legitimación de las prohibiciones» ${ }^{19}$.

El bien jurídico puede ser descrito como un objeto fundamental para la convivencia social externa. Sin embargo, no se puede profundizar más en su definición debido a que no existe un concepto que englobe todas las realidades que son susceptibles de ser catalogadas como tal ${ }^{20}$. Por ello, no permite ir más allá de las genéricas definiciones establecidas por algunos autores como «hechos o finalidades que son necesarios para el libre

${ }^{14}$ A. Martín Pardo, El bien jurídico protegido..., op. cit., p. 426.

15 S. Mir Puig, «Límites del normativismo...», op. cit., y J. M. SiLva SÁnchez, Aproximación al Derecho penal..., op. cit., pp. 268-269.

16 W. HASSEMER, «¿Puede haber delitos que no afecten...», op. cit., p. 103.

17 STC 105/1988, de 8 de junio.

18 SSTC 55/1996, de 28 de marzo, y 161/1997, de 2 de octubre. Principio en el que, para la mayoría de la doctrina española y alemana, adquiere anclaje constitucional la teoría de exclusiva protección de bienes jurídicos. Vid. W. Hassemer, «¿Puede haber delitos que no afecten...», op. cit., p. 97; J. M. SILVA SÁnCHEZ, Aproximación al Derecho penal..., op. cit., p. 267; S. Mir Puig, «Límites del normativismo...», op. cit., y J. A. LasCuRAín SÁnchez y M. RusConi (dirs.), El principio de proporcionalidad penal, Buenos Aires, Ad hoc, 2014.

19 R. Robles Planas, «Introducción a la edición española. Dogmática de los límites al Derecho penal», en R. Robles Planas (ed.), Limites al Derecho penal. Principios operativos en la fundamentación del castigo, Barcelona, Atelier, 2012, p. 23.

${ }^{20}$ En la actualidad se debate sobre la idea de si ciertas realidades como los sentimientos pueden constituir un bien jurídico legítimo. Sobre este tema vid. C. RoxIn, «El concepto de bien jurídico...», op. cit. 
desarrollo del individuo, la realización de sus derechos fundamentales y la funcionalidad de un sistema estatal que se basa en dichas metas» ${ }^{21}$, «posibilidades de satisfacción de las necesidades humanas» ${ }^{22}$, «presupuesto de la convivencia social a proteger por el Derecho penal» ${ }^{23}$. Tratar de ir más allá supone, tal y como han puesto de manifiesto algunos autores, una tarea avocada al fracaso ${ }^{24}$. Por tanto, aunque una de las objeciones más frecuentes que se suelen hacer contra el concepto de bien jurídico es su indefinición y su imposibilidad para enumerar detalladamente todas las realidades que pueden ser catalogadas como tal ${ }^{25}$, como acertadamente apunta Amelung, es ahí donde precisamente reside su fuerza y su capacidad para adaptarse a cambios espacio-temporales. Como apunta este autor, «gracias a esta característica, el dogma del bien jurídico se convierte en punto de conexión de la política con la dogmática, y el concepto de bien jurídico en un concepto complementario de la positividad del Derecho que traslada el dinamismo de lo político a la estabilidad del sistema jurídico» ${ }^{26}$.

Ahora bien, aunque no se pueda ofrecer un concepto que abarque todas las realidades susceptibles de ser consideradas como bien jurídico, lo cierto es que éste debe cumplir con una serie de características para poder llevar a cabo una crítica al legislador y servir como concepto de referencia respecto al de dañosidad social, ajustándose así a los postulados de un derecho penal material ${ }^{27}$. Para ello, el bien jurídico deberá hacer referencia a un objeto concreto de la realidad social (epígrafe II.1), debe poder ser lesionado a través de acciones individuales (epígrafe II.2) e integrar sólo aspectos de las realidades indispensables para la convivencia social externa (epígrafe II.3).

${ }^{21}$ C. Roxin, Strafrecht..., op. cit., p. 16.

22 J. Terradillos Basoco, «La satisfacción de necesidades...», op. cit., p. 136.

23 J. L. DíEz Ripollés, Derecho penal español..., op. cit., p. 22.

24 J. M. Silva SÁnchez, Aproximación al Derecho penal..., op. cit., p. 288.

25 C. Roxin, «El concepto de bien jurídico...», op. cit.

${ }^{26}$ K. Amelung, «El concepto "bien jurídico" en la teoría...», op. cit., p. 232.

27 S. Mir Puig, Introducción a las bases..., op. cit., p. 132; J. M. Silva Sánchez, Aproximación al Derecho penal..., op. cit., p. 267; P. R. LAURENZO COPELLO, «Recensión a J. M. Silva Sánchez...», op. cit., pp. 441-456, esp. p. 449; J. L. DíEz RIPOLLÉs, «La contextualización del bien jurídico...», op. cit., p. 35; J. TERRADILLOS BASOCO, «La satisfacción de necesidades...», op. cit., p. 124, y J. Bustos Ramírez, Manual de Derecho Penal..., op. cit., pp. 119-121. 


\section{CARACTERÍSTICAS DEL BIEN JURÍDICO Y DE SU LESIÓN EN UN DERECHO PENAL MATERIAL}

\subsection{Objeto concreto de la realidad social}

En concordancia con la teoría de la dañosidad social propuesta por Amelung, que afirma que el delito debe afectar a la convivencia social externa, el bien jurídico, como concepto de referencia, respecto al de daño social, debe recaer sobre un objeto concreto de la realidad social ${ }^{28}$. Por tanto, no depende de lo establecido por el legislador en la ley, lo que lo convertiría en un instrumento formal, incapaz de llevar a cabo cualquier crítica frente al mismo ${ }^{29}$. Sin perjuicio de que en un sistema democrático es sobre el legislador, como legítimo dueño del poder, sobre el que recae la labor de plasmar en la ley aquello considerado socialmente valioso, su labor es de transposición, no de creación de bienes jurídicos. Una vez trasladado a la ley, el juicio de valor elaborado por éste no pasa a integrar el concepto de bien jurídico ${ }^{30}$. Por eso, tal y como pone de manifiesto Laurenzo Copello, resulta metodológicamente incorrecto abordar su configuración como si fuera un elemento más del tipo que como el objeto material debe ser identificado en el propio precepto penal. Esto supone la necesidad de encontrar un objeto de tutela incluso a costa de elevar a la categoría de bien jurídico cualquier objeto difuso o abstracto, dando lugar así a su fracaso como objeto limitador de las intervenciones del legislador ${ }^{31}$.

Además, el bien jurídico debe estar dotado de concreción. No puede ser definido de manera difusa o abstracta, sino sintéticamente ${ }^{32}$. En rea-

${ }^{28}$ J. L. DíEz RipolLÉs, «La contextualización del bien jurídico...», op. cit., p. 35.

29 S. Mir Puig, Introducción a las bases..., op. cit., p. 132, y P. R. LAURENZO Copello, «Recensión a J. M. Silva Sánchez...», op. cit., p. 449. Sólo una concepción de bien jurídico basada en lo social puede tener capacidad limitadora.

${ }^{30}$ Lo que podría desembocar en su transformación en un ente ideal imposible de lesionar por acciones individuales y, por tanto, incapaz de llevar a cabo cualquier función crítica. Vid. S. Soto NavarRo, La protección penal de los bienes colectivos en la sociedad moderna, Granada, Comares, 2003, pp. 283-284, y J. M. SiLva Sánchez, Aproximación al Derecho penal..., op. cit., pp. $267-278$ y $285-293$.

${ }^{31}$ P. Laurenzo Copello, «Recensión a J. M. Silva Sánchez...», op. cit., p. 449.

32 Sobre la necesidad de concreción se pronuncian J. A. LASCURAín, «Bien jurídico y objeto...», op. cit., p. 125; R. AlCÁCER GUIRAO, ¿Lesión de bien jurídico..., op. cit., p. 21; S. Mir Puig, «Bien jurídico y bien jurídico-penal...», op. cit., p. 231; A. MarTín PARDO, El bien jurídico protegido..., op. cit., pp. 428-433, para quien el bien jurídico sirve para condensar en un concepto operativo las funciones sociales que se ven afectadas por las conductas delictivas (p. 424); J. Bustos Ramírez, Manual de Derecho Penal..., op. cit., p. 123, quien lo 
lidad, más que formulado de manera sintética, para cumplir con los postulados de un derecho penal material debe hacer referencia a estados de cosas u objetos concretos. La funcionalidad del bien jurídico se sustenta en que permite un acceso mental rápido y claro a lo protegido por la norma, y dicha ventaja no se dará en formulaciones demasiado amplias, abstractas o divagadoras que impiden verificar la lesividad de las conductas que lo afectan y que, por ende, lo espiritualizan hasta convertirlo en un elemento formal ${ }^{33}$.

En la actualidad, son cada vez más comunes las definiciones de bienes jurídicos a través de fórmulas demasiado omnicomprensivas o difusas que suelen ir aparejadas a los de carácter colectivo, pero que a veces también se dan en los bienes jurídicos individuales. Así, «el orden socioeconómico», «la Administración de Justicia», «el correcto funcionamiento de la Administración Pública», no son realidades susceptibles de ser lesionadas por acciones individuales y, por tanto, no pueden ser consideradas como bienes jurídicos legítimos ${ }^{34}$. Dichas realidades no constituyen el bien jurídico de ninguna figura delictiva, sino el sistema social en el que éste se encuentra, en el que ejerce su funcionalidad práctica. Para llevar a cabo una identificación adecuada del mismo habrá que analizar en dicho sistema social cuáles son los principios o aspectos concretos que son funcionales y que se ven lesionados a través de determinadas conductas consideradas dañosas.

Para servir de soporte a la idea de lesividad, el bien jurídico tampoco debe ser concebido como un objeto ideal o espiritualizado perteneciente al mundo de las ideas e imposible de lesionar por acciones individuales. Aunque el bien jurídico goza de un cierto componente ideal, en el sentido de que encarna un juicio de valor positivo sobre un determinado aspecto de la realidad, dicho juicio de valor no pasa a integrar el concepto de bien jurídico, sino sólo el objeto sobre el que éste recae. Por tanto, aunque a menudo se formule el objeto de tutela en términos como «honor», «vida»,

define como «síntesis normativa determinada de una relación social concreta y dialéctica»; R. HEFENDEHL, «El bien jurídico como eje material de la norma penal», en R. HeFENDEHL (ed.), La teoría del bien jurídico. ¿Fundamento de legitimación del Derecho penal o juego de abalorios dogmático?, Barcelona-Madrid, Marcial Pons, 2007, p. 181; J. TerRadillos BasoCO, «La satisfacción de necesidades...», op. cit., p. 129, y A. M. PRIETO DEL PINo, El Derecho penal ante el uso de información privilegiada en el mercado de valores, Cizur Menor, Thomson Aranzadi, 2004, p. 241.

${ }_{33}$ Son las formulaciones vagas o demasiado generalizadoras las que ponen en riesgo el propio concepto de bien jurídico. Vid. W. Hassemer, «¿Puede haber delitos que no afecten...», op. cit., p. 96.

34 A. M. Prieto del Pino, El Derecho penal ante el uso..., op. cit., p. 241. 
«salud», los bienes jurídicos son las concretas parcelas de la realidad social susceptibles de alteración por acciones individuales ${ }^{35}$. Por eso, como aclara Mir Puig, el Derecho penal no ha de proteger el «valor vida» en cuanto tal, sino las vidas concretas de los ciudadanos. Pero no como meros datos biológicos (lo que constituiría el objeto de la acción), sino por el valor funcional que suponen para sus titulares y para la sociedad ${ }^{36}$.

Un ejemplo de bien jurídico que no alude a un objeto real es el defendido por el autor alemán Günter Jakobs y sus discípulos, que sitúa el daño producido por el delito no en la lesión de objetos valorados socialmente, sino en la defraudación de expectativas legítimas que produce el incumplimiento de las normas. Por tanto, el bien jurídico protegido se corresponde con la validez fáctica de la norma, que es lo que, según el autor, garantiza el funcionamiento de la vida social ${ }^{37}$. Esta propuesta nos vuelve a abocar a un derecho penal formal en la medida en que no es capaz de servir de soporte a la idea de lesividad, dado que no selecciona a priori cuáles son las expectativas normativas que pueden integrar legítimamente el Derecho penal más allá de la norma misma ${ }^{38}$.

En contra de la teoría de Jakobs se puede señalar que el Derecho penal no aspira al mantenimiento de sus normas, sino a salvaguardar presupuestos inequívocamente imprescindibles para la convivencia social. Considerar que lo dañoso socialmente es la defraudación de expectativas normativas que se produce con la infracción de la norma misma supone llevar a cabo una valoración per se de la norma penal y de la restricción de libertad que la misma conlleva. Sin embargo, las normas no son un bien en sí mismas que legitimen la intervención penal, sino, al contrario, un «mal» necesitado de justificación ${ }^{39}$. Por tanto, la postura que mantiene esta escuela es difícilmente aceptable si se parte de que el Derecho es un sistema normativo al servicio de los ciudadanos y no orientado al mantenimiento de sus propias normas ${ }^{40}$. A diferencia de la vigencia fáctica de la norma, el bien jurídico como objeto de la realidad social afectado por el delito, constituye una garantía para el individuo frente al Estado en cuanto justifica de alguna manera el porqué de la intervención estatal, acotando el contenido

35 S. Soto Navarro, La protección penal de los bienes..., op. cit., p. 290.

36 S. Mir Puig, Introducción a las bases..., op. cit., p. 140.

37 G. Jakobs, Strafrecht Allgemeiner Teil. Die Grundlagen und die Zurechnungslehre, 2. ${ }^{a}$ ed., Berlin, De Gruyter, 1993, p. 36. Para ver específicamente la exposición de su teoría vid. G. JAKOBS, «¿Qué protege el Derecho penal...», op. cit., pp. 23-42.

38 R. AlcÁcer GuIrao, ¿Lesión de bien jurídico..., op. cit., p. 117.

39 S. Mir PUIG, «Límites del normativismo...», op. cit.

40 Ibid. 
material de las normas penales. De esta manera, el bien jurídico se erige como un argumento legítimo a la hora de justificar la imposición de una pena respecto al que ha de soportarla; es lo que motiva la fuerte reacción por parte del ordenamiento, la razón de la coacción penal ${ }^{41}$.

La propuesta de Jakobs elimina mecanismos que controlen la legitimidad de las normas penales en la teoría jurídica del delito, lo que supone un vaciamiento de contenido material del Derecho penal y un retroceso a periodos históricos que parecían superados ${ }^{42}$. Como establece Corcoy Bidasolo, podremos debatir sobre la capacidad de crítica del bien jurídico, pero dicha función le es totalmente ajena sin ninguna duda al mantenimiento de expectativas normativas ${ }^{43}$. Por ello, dada la situación de sobreabundancia legislativa por la que atraviesa este sector del ordenamiento, tal y como pone de manifiesto Alcácer Guirao, «dudo que sea de provecho para la dogmática sustituir un concepto de delito que es capaz de plasmar el componente material de lo lesivo, y, en tanto es así, de la razón esencial que lo hace merecedor de pena, por un concepto de carácter formal, con tal grado de abstracción que, a fuerza de pretender abarcar todos los presupuestos de la sanción, acaba por vaciarse de contenido material» $\gg^{44}$.

Otro ejemplo de bien jurídico que no alude a un objeto real y que, por consiguiente, no puede ser lesionado por acciones individuales es aquél formulado en términos de confianza por parte de la comunidad en el correcto funcionamiento o buena imagen de una determinada institución. Se trata de un sentimiento colectivo que ha sido elevado a la categoría de bien jurídico incluso por teóricos, tanto españoles como alemanes, defensores de la capacidad crítica de dicho instrumento ${ }^{45}$. Así, Hefendehl

${ }^{41}$ S. Soto NavarRo, La protección penal de los bienes..., op. cit., p. 170, y E. Peñaranda RAMOS, «Sobre la influencia del funcionalismo y la teoría de los sistemas en las actuales concepciones de la pena y del concepto de delito», Doxa. Cuadernos de Filosofía del Derecho, núm. 23 (2003), pp. 289-321.

${ }_{42}$ M. Alonso Álamo, «Bien jurídico material...», op. cit., p. 99.

${ }^{43}$ M. CorCOY Bidasolo, «Expansión del Derecho penal y garantías constitucionales», Revista de Derechos Fundamentales, núm. 8 (2012), pp. 45-76. Así, la autora se plantea: «¿Quién y por qué critica determinadas normas? ¿Cuál es el criterio para negar su validez? ¿No ser un elemento esencial para la vida social? ¿El concepto "elemento esencial para la vida social" no es una forma de describir el bien jurídico-penal?».

${ }^{44}$ R. AlCácer Guirao, ¿Lesión de bien jurídico..., op. cit., p. 107.

${ }^{45}$ En la doctrina española ha sido defendido por E. BACIgAluPO ZAPATER, «Sobre la reforma de los delitos de los funcionarios», Documentación jurídica, num. 37/40, vol. 2 (1983), p. 1099. En la doctrina alemana, R. HEFENDEHL, «El bien jurídico como eje material...», op. cit., p. 190, y F. Loos, «El bien jurídico en los delitos de cohecho», en K. Amвos 
pone de manifiesto que la confianza desde un punto de vista sociopsicológico en el aparato funcionarial es fundamental para el efectivo funcionamiento de la Administración Pública y que ésta debe cumplir un cierto nivel de confianza para que uno se ponga en sus manos ${ }^{46}$. Sin embargo, tras un análisis pormenorizado del mismo se puede afirmar que nos avoca a la misma situación que la teoría de Jakobs, ya que la confianza en el correcto funcionamiento de una institución es la otra cara de la moneda de la vigencia fáctica de las normas ${ }^{47}$. La confianza en el funcionamiento de una institución carece de carácter real no porque no sea perceptible por los sentidos, sino porque es un estado de conciencia que por regla general existe en una sociedad cuando la norma se cumple ${ }^{48}$. Por tanto, es un efecto del adecuado funcionamiento de las normas, pero no lo que éstas tutelan en cada una de las figuras delictivas ${ }^{49}$. El mismo problema se podría predicar de los bienes jurídicos definidos en términos de «sentimientos de seguridad colectiva» ${ }^{50}$.

El carácter irreal de este bien jurídico impide verificar su lesión empíricamente porque no permite conocer cuándo una determinada acción produce desconfianza, qué condiciones deben darse para que esto ocurra y qué grado de desconfianza es necesario para que se produzca para que tenga luego el tipo penal ${ }^{51}$. De hecho, la desconfianza se produce más bien como consecuencia de la publicidad que de la conducta en sí. Por tanto, si la publicidad es lo que produce el efecto dañoso podrían considerarse inocuas conductas que permanecieran ajenas a la opinión pública. Asimismo, sería recomendable que la prensa no informara sobre casos de corrupción, lo que es del todo impensable en un sistema democrático, además de contribuir a la configuración de un sistema opaco y poco

y H. RADKE (coords.), Estudios filosófico-jurídicos y penales del profesor Fritz Loos. Homenaje a sus setenta años, Chile, Editorial Jurídica de Chile, 2009, p. 156.

${ }^{46}$ R. HefENDEHL, «El bien jurídico como eje material...», op. cit., p. 190.

47 Así lo pone de manifiesto K. AmELung, «El concepto "bien jurídico" en la teoría...», op. cit., pp. 250 y 251.

${ }^{48}$ Ibid. Una crítica detallada a este bien jurídico en B. J. FeIjoo SÁncheZ, «Sobre la crisis del bien jurídico...», op. cit., pp. 8-9, nota 5 .

${ }_{49}$ B. J. Feijoo SÁnCHEZ, «Sobre la crisis del bien jurídico...», op. cit., pp. 8-9, nota 5.

50 S. Soto Navarro, La protección penal de los bienes..., op. cit., pp. 179-180.

${ }^{51}$ La desconfianza que se deriva de la conducta concreta es un efecto difícilmente mensurable que dificulta la identificación de la lesión. Vid. S. SOTO NAVARRO, La protección penal de los bienes..., op. cit., p. 308. Por eso, los autores que defienden este bien jurídico consideran que el mismo no puede ser lesionado por acciones individuales, lo que les lleva a recurrir al pensamiento de la acumulación para identificar unidades lesionables del bien jurídico. Vid. R. HEFENDEHL, «El bien jurídico como eje material...», op. cit., p. 195. 
transparente que precisamente produce el efecto de aumentar los delitos en este ámbito ${ }^{52}$.

Ahora bien, puesto de manifiesto que el bien jurídico no lo pueden integrar valores, ideas $\mathrm{u}$ otros objetos difusos u omnicomprensivos por carecer de contenido real, tampoco lo constituyen exclusivamente objetos materiales dotados de corporeidad física ${ }^{53}$. La realidad no sólo se compone de objetos materiales, sino también de otros existentes en la realidad social. Por tanto, el objeto de la realidad al que se refiere el bien jurídico debe ser entendido en un sentido sociológico y no físico. Como expone el propio Amelung, para determinar la dañosidad social que un determinado comportamiento irroga en un sistema es necesario atender a las razones por las éste es valorado socialmente, es decir, a los objetivos a los que sirve ${ }^{54}$. Y lo valorado socialmente puede ser tanto real como de carácter normativo ${ }^{55}$. En el mismo sentido señala Hefendehl que la alternativa a ideal no es físico, sino real, y la realidad no sólo se compone de objetos físicos, sino también de fenómenos psíquico-intelectuales ${ }^{56}$. Por tanto, un bien jurídico para ser elevado a la categoría de tal no tiene porqué ser perceptible por los sentidos ${ }^{57}$, sino que el único requisito que debe cumplir es su pertenencia a la realidad social ${ }^{58}$.

\subsection{Carácter lesionable a través de acciones individuales}

En concordancia con el concepto de bien jurídico expuesto, su lesión también debe tener contenido real en el sentido que debe ser verificable empíricamente. Es decir, debe producir un efecto externo objetivamente constatable más allá de la infracción de la norma misma ${ }^{59}$. Por tanto, debe

\footnotetext{
52 A. Asúa BatARrita, «La tutela penal del correcto funcionamiento...», op. cit., p. 22.

$53 \mathrm{M}$. KAHLO, «Sobre la relación entre el concepto de bien jurídico y la imputación objetiva en Derecho penal», en R. HEFENDEHL (coord.), La teoría del bien jurídico. ¿Fundamento de legitimación del Derecho penal o juego de abalorios dogmático?, Barcelona-Madrid, Marcial Pons, 2007, pp. 55 y 56.

${ }^{54}$ K. Amelung, Rechtsgüterschutz und Schutz..., op. cit., p. 189.

55 Ibid., p. 339.

${ }^{56}$ R. HEFENDEHL, «Las jornadas desde la perspectiva de un partidario del bien jurídico», en R. HEFENDEHL (coord.), La teoría del bien jurídico. ¿Fundamento de legitimación del Derecho penal o juego de abalorios dogmático?, Barcelona-Madrid, Marcial Pons, 2007, p. 411, y K. Amelung, Rechtsgüterschutz und Schutz.., op. cit., p. 189.

57 S. Mir Puig, Introducción a las bases..., op. cit., p. 134.

58 S. Soto NavarRo, La protección penal de los bienes..., op. cit., p. 307.

${ }^{59}$ Ibid., p. 282.
} 
ser interpretada en un sentido ideal como oposición a la norma, pero tampoco exige una modificación perceptible en el mundo exterior basada en las leyes de la causalidad. La lesión, al igual que el bien jurídico, debe ser interpretada en un sentido sociológico y éste debe producir efectos, visibles o no, en el sistema social.

Esto implica que la lesión no siempre debe identificarse con un menoscabo físico o con la destrucción del bien jurídico, lo que suele ser habitual en aquellos bienes jurídicos que llevan a cabo su función social conservando su plena integridad física. La lesión de los bienes jurídicos que carecen de sustrato físico no consiste en la destrucción o desaparición del mismo, sino en la afección de su funcionalidad, de la misión que el mismo desempeña ${ }^{60}$. Así, los bienes jurídicos que carecen de sustrato físico no se destruyen, sino que se «comprimen» mientras actúa sobre ellos la acción típica, como sucede, por ejemplo, en relación a la libertad ambulatoria $^{61}$. Que el concepto de dañosidad social no se equipare a la destrucción o desaparición del bien es necesario en los bienes jurídicos individuales, pero resulta fundamental en los de carácter colectivo, especialmente en aquellos configurados normativamente como los que hacen referencia a instituciones públicas. En estos casos, la lesión de la Administración Pública o de la Administración de Justicia consistirá en la parálisis de su actividad, en la disfunción de la misma o en la pérdida de sus características esenciales $^{62}$.

Además, el bien jurídico no debe poder ser lesionado sin más, sino que debe poder serlo a través de acciones individuales. Es decir, tiene que constatarse una situación anterior y otra posterior a la actuación del sujeto sobre el mismo, lo que, como se ha advertido anteriormente, no es posible si éste es definido en términos omnicomprensivos o espiritualizados. Definido como «la Administración de Justicia», «el buen funcionamiento de la Administración Pública», «la vigencia fáctica de la norma» o «la confianza en el correcto funcionamiento de determinadas instituciones» ${ }^{63}$, el bien jurídico no puede ser alcanzado por acciones individuales, por lo que la doctrina que defiende estos objetos de protección se ve obligada a recurrir a mecanismos que le permitan concretar unidades lesionables. Para llevar a cabo esta tarea de concreción acuden a la teoría de los bienes jurídicos intermedios o el pensamiento de la acumulación.

${ }^{60}$ A. M. PRieto del Pino, El Derecho penal ante el uso..., op. cit., p. 244.

${ }^{61}$ Ibid.

${ }_{62}$ Ibid., nota 115.

63 S. Soto NAvARro, La protección penal de los bienes..., op. cit., p. 319. 
La teoría de los bienes jurídicos intermedios fue esbozada por Schünemann para identificar unidades lesionables de bienes jurídicos definidos de manera genérica como «la función pública», «el funcionamiento de la Administración de Justicia» o «el orden socioeconómico» ${ }^{64}$. Según ésta, dichos entes constituyen bienes jurídicos espiritualizados o mediatos que no pueden ser lesionados por acciones individuales, por lo que necesitan de un «representante»o «bien jurídico inmediato» que lo acerque a un plano más concreto Así, estos autores mantienen un sistema de doble bien jurídico que acaba dando problemas a la hora de interpretar los tipos penales ${ }^{65}$.

Por su parte, el pensamiento de la acumulación fue concebido por Kuhlen para ciertos delitos medioambientales, especialmente para el caso del tipo de contaminación de aguas (Gewässerverunreinigung) del $\$ 324$ del Código Penal alemán ${ }^{66}$. Sin embargo, después fue utilizado para delitos contra determinadas instituciones como la Administración Pública o la Administración de Justicia. Esto se debe a que hay quien considera que sólo un verdadero deterioro institucional producido por una reiteración de conductas en el seno de las mismas es capaz de lesionar la Administración Pública o la Administración de Justicia ${ }^{67}$. Según esta teoría, son delitos cumulativos

\footnotetext{
${ }^{64}$ Señala este autor que «las concepciones sociales han constituido un bien intermedio espiritualizado cuya lesión presenta un desvalor propio y que por ello tiende un puente con los delitos de lesión en sentido estricto (es decir, aquellos con un bien jurídico materialmente aprehensible)». Vid. B. SchÜnemann, «Moderne Tendenzen in der Dogmatik der Farhlässigkeits- und Gefährdungs-delikte», JA (1975), pp. 435-798, esp. p. 798. En la doctrina española vid. T. Rodríguez Montañés, Delitos de peligro, dolo e imprudencia, Madrid, Centro de Estudios Judiciales, 1994, p. 301.

${ }^{65}$ A pesar de que supuestamente el bien jurídico espiritualizado no ejerce funciones dogmáticas, sino que es relegado a una mera ratio legis del precepto. Una crítica a esta concepción doctrinal en A. M. PRIETo del PINo, El Derecho penal ante el uso..., op. cit., pp. 240-241.

${ }^{66}$ L. KuHLEN, «Der Handlungserfolg der strafbaren Gewässerverunreinigung ( $\$ 324$ StGB)», Goltdammer's Archiv für Strafrecht, Heidelberg, Decker, 1986, pp. 389-408. Han defendido el pensamiento de la acumulación posteriormente en la doctrina R. HEFENDEHL, Kollektive Rechtsgüter im Strafrecht, Köln-Berlin-Bonn-München, Carl Heymanns, 2002, pp. 183-193, y A. vON HiRSCH y W. WOHLERS, «Teoría del bien jurídico y estructura del delito. Sobre los criterios de una imputación justa», en R. HeFendeHL (coord.), La teoría del bien jurídico. ¿Fundamento de legitimación del Derecho penal o juego de abalorios dogmático?, Barcelona-Madrid, Marcial Pons, 2007, pp. 299-304.

${ }^{67}$ Han utilizado argumentos encuadrables en el pensamiento de la acumulación para la Administración Pública I. Olaizola Nogales, El delito de cohecho, Valencia, Tirant lo Blanch, 1998, p. 102; B. J. Feijoo SÁnCHEZ, «Delitos contra la Administración Pública...», op. cit., y J. C. Ferré Olivé, «Corrupción y delitos contra la Administración Pública», en J. C. Ferré Olivé (dir.), Delitos financieros, fraude y corrupción en Europa, vol. III, Salamanca, Universidad de Salamanca, 2002, p. 20, quien considera que es difícil o prácticamente imposible que una acción aisladamente considerada pueda lesionar a la Administración Pública en su conjunto.
} 
aquellos en los que la conducta en cuestión sólo produce menoscabos relevantes del bien jurídico en la medida que tienen lugar de forma reiterada o acumulada a otras conductas de la misma naturaleza. Por tanto, la represión por el derecho penal de comportamientos individuales vendría motivada para evitar una realización generalizada de las mismas, lo que sí perturbaría gravemente el bien jurídico en cuestión. Sin embargo, esta teoría pone en entredicho principios clásicos del Derecho penal como el de responsabilidad por el hecho o el de imputación subjetiva ${ }^{68}$, y, además, al igual que la anterior, resulta innecesaria si el bien jurídico se configura como un objeto de la realidad social dotado de concreción y susceptible de ser lesionado a través de acciones individuales ${ }^{69}$. Por ello, como acertadamente señala Roxin, dicha construcción, al igual que la de los bienes jurídicos intermedios, acaba sirviendo únicamente para legitimar pseudobienes jurídicos ${ }^{70}$.

\subsection{Sólo aspectos de la realidad fundamentales para la convivencia social externa}

Como ya se ha expuesto anteriormente, el juicio de lesividad tiene como objeto de referencia la existencia de un bien jurídico legítimo. Ambos, lesividad y bien jurídico, están estrechamente relacionados, pues el análisis sobre la lesividad de la conducta se remite al objeto socialmente valorado ${ }^{71}$. De esta manera, una conducta no puede ser considerada dañosa si no lesiona un objeto digno de protección suficientemente importante para la convivencia social con las características anteriormente expuestas.

${ }^{68}$ S. Soto Navarro, La protección penal de los bienes..., op. cit., p. 184, y A. M. PrIETO DEL PINo, El Derecho penal ante el uso..., op. cit., p. 241. Intenta salvar esa crítica, a mi juicio sin mucho éxito, R. HefEndeHL, «El bien jurídico como eje material...», op. cit., p. 195.

${ }^{69}$ Por eso no es extraño que el pensamiento de la acumulación sólo acompañe a formulaciones de bienes jurídicos abstractas como «la función pública»o «la confianza en el funcionamiento de la Administración». Así lo pone de manifiesto J. Bustos Ramírez, Control social..., op. cit., p. 158.

${ }^{70}$ Así lo pone de manifiesto Roxin para la teoría de la acumulación, pero ésta también podría ser extrapolada para la de los bienes jurídicos intermedios. Vid. C. Roxin, Strafrecht..., op. cit., 39.

${ }^{71}$ En este sentido se ha pronunciado la mayoría de la doctrina. Vid. J. TerRadillos BASOCO, «La satisfacción de necesidades...», op. cit., p. 134; M. A. ABANTO VÁSQUEZ, «Acerca de la teoría...», op. cit., p. 4, y R. AlCÁCER GUIRAO, ¿Lesión de bien jurídico..., op. cit., p. 21. En sentido contrario se ha pronunciado Martín Pardo, que considera el concepto de dañosidad social como un concepto autónomo y previo a la identificación del bien jurídico. Vid. A. Martín PARDO, El bien jurídico protegido..., op. cit., p. 428. 
En base al principio de lesividad, no atentarían contra la convivencia social externa aquellos comportamientos que no afectan a la realización de planes vitales ajenos y tampoco aquellos que, aun incidiendo en tales planes, forman parte de la propia vida privada y no requieren ningún tipo de reacción social ${ }^{72}$. Por tanto, evita que el Derecho penal pueda juzgar acciones que deben quedar en el fuero de la conciencia ${ }^{73}$. Por ello, tradicionalmente han sido identificados por la doctrina como instrumentos que sirven al problema de la separación entre derecho y moral ${ }^{74}$. Para muchos, la teoría de exclusiva protección de bienes jurídicos tiene como logros la desaparición del Derecho penal de la mayor parte de bienes jurídicos meramente morales durante el proceso de despenalización que tuvo lugar durante los setenta y los ochenta en Europa, especialmente respecto a aquellas conductas como la alcahuetería, la homosexualidad, el adulterio u otras relacionadas con la moral sexual ${ }^{75}$.

Sin embargo, este papel que tradicionalmente le asigna la doctrina para eliminar del Derecho penal todo contenido moral debe ser matizado. La moral, como conjunto de valores compartidos por todos, no debe ser apartada del Derecho. De hecho, la mayor parte de los preceptos penales como el homicidio, el robo o la estafa suscitan un reproche moral por parte de la sociedad ${ }^{76}$. En realidad, lo que se pretende retirar no es cualquier contenido moral del Derecho, sino sólo las conductas que, por su contenido exclusivamente ético, no afecten a la convivencia social externa ${ }^{77}$.

72 J. L. Díez Ripollés, La racionalidad de las leyes penales, Madrid, Trotta, 2013, p. 138.

73 Ibid., p. 138; H. H. JeschecK, Tratado de Derecho penal: parte general, traducción y adiciones de S. Mir Puig y F. Muñoz Conde, Barcelona, Bosch, 1981, p. 11, y J. M. Silva SÁncheZ, Aproximación al Derecho penal..., op. cit., p. 269.

${ }^{74}$ J. L. Díez RIPOLLÉs, La racionalidad..., op. cit., p. 138.

75 E. Gimbernat Ordeig, en R. Alcácer Guirao, ¿Lesión de bien jurídico o lesión del deber? Apuntes sobre el concepto material del delito, Barcelona, Atelier, 2003, p. 13.

76 A. MarTín PARDo, El bien jurídico protegido..., op. cit., p. 434.

77 En realidad, lo que pretende el eslogan «separación entre derecho y moral» propio de la teoría de exclusiva protección de bienes jurídicos es atacar la imposición de una determinada moral por medio del Derecho penal, pero «siendo el Derecho una técnica de regulación social en los países democráticos, éste habrá de organizar la convivencia social de un modo que se corresponda con la teoría ética normativa que sirva de base al sistema». Vid. I. Ortiz de Urbina Gimeno, La excusa del positivismo. La presunta superación del «positivismo» y el «formalismo» por la dogmática penal contemporánea, Madrid, Civitas, 2007, pp. 62-63. Que el Derecho penal se encuentre refrendado por concepciones morales es incluso aconsejable, pues, como pone de manifiesto Robinson a lo largo de su obra, si hay algún motivo por el que los ciudadanos cumplen las normas es por el hecho de que se ajustan a concepciones morales asumidas por todos y no por el miedo a la imposición de una pena. Vid. P. H. Robinson, Principios distributivos del Derecho penal. A quién debe sancionarse y en qué medida, Madrid-Barcelona-Buenos Aires, Marcial Pons, 2012. 
Ahora bien, aunque la misión del bien jurídico y del principio de lesividad al mismo referido parecen estar claras, su puesta en práctica resulta más problemática de lo que parece, pues supone adoptar una decisión valorativa sobre cuál es el nivel de dañosidad que como sociedad estamos dispuestos a tolerar, y ese límite se halla fuertemente condicionado por el momento histórico y el tipo de sociedad que lo lleva a $\mathrm{cabo}^{78}$. Lo que debe quedar incluido o excluido en el Derecho penal en base al principio de lesividad se encuentra en continua fluctuación porque «nuestra conciencia moral evoluciona» ${ }^{79}$. Por tanto, no existen bienes jurídicos «eternos» y «necesarios per se», sino dependientes de los criterios valorativos del sistema social de referencia. De hecho, como argumenta Laurenzo Copello, «una adecuada comprensión del sentido del bien jurídico presupone la adaptación de éste a cada situación histórica, pues, en definitiva, no se trata sino de localizar situaciones o estados de cosas que precisamente por su "funcionalidad" a un determinado sistema social - geográfica y temporalmente delimitado- adquieren una especial entidad y deben ser conservadas» ${ }^{80}$.

Por tanto, el bien jurídico como concepto está abierto al cambio y a los progresos sociales, lo que convierte a este instrumento, a pesar de su contenido valorativo, en objeto de discusión empírica ${ }^{81}$. Y es éste, sin duda, el mayor reto pendiente con respecto a dicho instrumento. Los efectos sociales dañosos que irroga un determinado comportamiento en un sistema social en la medida de lo posible deben ser apoyados por argumentos basados en la realidad social ${ }^{82}$. Sin embargo, el legislador ha evitado crear cualquier tipo de debate científico en torno al mismo, siendo poco habitual que acuda a estudios sociológicos o criminológicos para refrendar determinadas decisiones legislativas. A menudo en las exposiciones de motivos se justifica formalmente la dañosidad social de una conducta aludiendo a la afectación de un supuesto bien jurídico sin apoyar dicho juicio de valor en información aportada por las ciencias sociales, impidiendo la posibilidad de suscitar un debate científico en torno al mismo. De esta forma, el legislador convierte este instrumento en «un fetiche cuya sola mención es

78 J. L. DíEz Ripollés, La racionalidad..., op. cit., p. 138.

79 G. Stratenwerth, «La criminalización en los delitos contra bienes jurídicos colectivos», en R. HeFENDEHL (ed.), La teoría del bien jurídico. ¿Fundamento de legitimación del Derecho penal o juego de abalorios dogmático?, Barcelona-Madrid, Marcial Pons, 2007, p. 370, y J. M. Silva SánCHeZ, Aproximación al Derecho penal..., op. cit., p. 89.

80 P. R. Laurenzo Copello, «Recensión a J. M. Silva Sánchez...», op. cit., p. 449. En igual sentido J. TeRRADILLOS BASOCO, «La satisfacción de necesidades...», op. cit., p. 128.

${ }^{81}$ C. Roxin, Strafrecht..., op. cit., p. 32.

${ }^{82}$ H. H. Jescheck, Tratado de Derecho penal..., op. cit., p. 34. 
capaz de fundamentar cualquier intervención, haciendo que éste carezca de poder discriminatorio real» ${ }^{83}$.

Una de las objeciones que los detractores del bien jurídico han esgrimido en contra de su capacidad crítica es que, una vez eliminados de los Códigos Penales europeos todos los bienes jurídicos meramente morales, difícilmente éste volverá a ejercer un papel tan activo como el que llevó a cabo durante el proceso de despenalización en el pasado ${ }^{84}$. Sin embargo, como ya se ha ido poniendo de manifiesto, el bien jurídico no se limita exclusivamente a eliminar del Derecho penal intereses meramente morales, sino también otros (algunos de los cuales ya se han expuesto) que por sus características difícilmente puedan ser elevados a la categoría de tal ${ }^{85}$. En la actualidad existen numerosos tipos delictivos sobre los que ni la doctrina ni la jurisprudencia se ponen de acuerdo sobre cuál es su objeto de protección ${ }^{86}$. Asimismo, han proliferado figuras delictivas que protegen sentimientos colectivos o aluden a intereses o valores en el ámbito de la vida económica, del medio ambiente..., demasiado difusos o carentes de contenido $^{87}$. Por tanto, es precisamente respecto a estas mismas frente a las que debe ejercer una labor crítica el concepto de bien jurídico.

Otra de las objeciones que se han planteado respecto a la capacidad del bien jurídico para eliminar el contenido moral del Derecho penal es que ni si quiera ha sido mérito del mismo la consecución de dicho logro, pues en otros países que por su tradición jurídica les es ajeno dicho concepto, como Francia o los países anglosajones, tampoco reprimen penalmente conductas como la homosexualidad o el adulterio ${ }^{88}$. En realidad, como respuesta a esta crítica se puede decir que esto se debe a que la función que ha llevado a cabo el bien jurídico en los ordenamientos de tradición continental ha sido realizada a otras figuras análogas en otros ordenamientos jurídicos $^{89}$. Así el harm principle es el equivalente funcional del bien jurídico

83 J. L. Díez Ripollés, La racionalidad..., op. cit., p. 20.

84 B. J. FeIJoo SÁncheZ, «Sobre la crisis del bien jurídico...», op. cit., y W. Frisch, «Bien jurídico, derecho...», op. cit., p. 310. Responde a esta crítica también C. RoxIN, «El concepto de bien jurídico...», op. cit.

${ }^{85}$ El principio de lesividad abarca más aspectos además de la mera distinción entre el Derecho y la moral. Vid. J. L. Díez RIPOLLés, La racionalidad..., op. cit., p. 138.

${ }^{86}$ Ello se advierte, según Corcoy Bidasolo, especialmente en algunos de los delitos socioeconómicos, en la aparición de nuevos delitos de carácter moralista y en otros que tienen la función procesal de facilitar la investigación y/o la condena de determinados sujetos. Vid. M. Corcoy Bidasolo, «Expansión del Derecho penal...», op. cit.

${ }^{87}$ G. SEHER, «La legitimación de normas penales...», op. cit., p. 69.

88 B. J. FeijOo SÁnCHEZ, «Sobre la crisis del bien jurídico...», op. cit.

89 A. vON Hirsch, «El concepto de bien jurídico y el "principio del daño"», en 
en aquellos de tradición anglosajona. En cualquier caso, lo cuestionable de dicha observación radica en que confunde dos planos de análisis: el social y el normativo. La evolución colectiva a lo largo de los años tienen lugar en el plano de lo social, mientras que el bien jurídico ejerce su funcionalidad práctica en el ámbito normativo. Efectivamente, han sido los cambios sociales a lo largo del tiempo lo que ha ido poniendo de manifiesto la necesidad de eliminar ciertos contenidos del Derecho penal, pero el bien jurídico como instrumento normativo ha contribuido a poner de manifiesto el desfase existente entre la realidad social y la ley.

\section{FUNCIÓN POLÍTICO-CRIMINAL LIMITADA}

Llegados a este punto se puede afirmar que, cumpliendo con las características anteriormente expuestas, el bien jurídico puede desarrollar una función crítica o político-criminal en el sentido de mantener al margen del Derecho penal realidades que no cumplen con las características previamente expuestas. Esta concepción permite rechazar como objeto de protección penal la vigencia de la norma, determinadas valoraciones éticas sin consecuencias sociales externas u otros entes abstractos o espiritualizados imposibles de lesionar a través de conductas individuales como la confianza socialmente relevante en el funcionamiento de determinadas instituciones $u$ otros objetos demasiado amplios u omnicomprensivos como el orden socioeconómico o la función pública.

Ahora bien, una vez retirados aquellos contenidos que por sus características no pueden constituir un bien jurídico legítimo, el margen de actuación para criminalizar conductas del legislador sigue siendo bastante amplio. Por tanto, se puede afirmar que el papel que puede llevar a cabo como instrumento de contención del ius puniendi es limitado ${ }^{90}$. El bien jurídico no es un oráculo al que preguntar cuándo estamos ante una criminalización ilegítima y tampoco es capaz de resolver todos los problemas a los que se enfrenta el Derecho penal actual. Es un instrumento de legitimación, pero no el único y, por tanto, no es capaz por sí solo de sustentar una teoría de la legislación, indicando al legislador qué conductas pueden ser objeto de protección penal. En este sentido, la crítica que hacen algu-

R. HeFendehl (ed.), La teoría del bien jurídico. ¿Fundamento de legitimación del Derecho penal o juego de abalorios dogmático?, Barcelona-Madrid, Marcial Pons, 2007, p. 43.

90 W. HAssemer, «¿Puede haber delitos que no afecten...», op. cit., p. 98, y R. AlCÁCER GuIRaO, ¿Lesión de bien jurídico..., op. cit., p. 115. 
nos autores está totalmente fundamentada: el principio de exclusiva protección de bienes jurídicos no es capaz de indicar al legislador sobre qué realidades y hasta dónde llevar a cabo una intervención penal ${ }^{91}$.

Sin embargo, no está muy claro contra quien dirigen esa crítica los denominados «detractores» del bien jurídico porque, en realidad, nadie en la doctrina ha defendido nunca un protagonismo del bien jurídico como instrumento político criminal tan exagerado ${ }^{92}$. Para saber qué realidades pueden ser protegidas legítimamente por el Derecho penal no se puede acudir únicamente a la teoría de exclusiva protección de bienes jurídicos, sino a otros principios de carácter axiológico y de carácter utilitarista que, junto con el bien jurídico, pueden aportar una información valiosa sobre qué realidades pueden ser legítimamente castigadas por este sector del ordenamiento ${ }^{93}$. Por ejemplo, principios como el de fragmentariedad y el de subsidiariedad son muy útiles para arrojar luz en este sentido ${ }^{94}$. Y en este aspecto fundamental es donde coinciden tanto detractores como partidarios del bien jurídico, siendo, por tanto, la supuesta crisis del bien jurídico una discusión doctrinal más aparente que real.

En Derecho penal el bien jurídico constituye un dogma; un precepto penal es ilegítimo si no protege un objeto digno de tutela. Sin embargo, el resto del ordenamiento también se orienta a la protección de objetos valorados socialmente y no de entes ideales o puramente morales ${ }^{95}$. Por tanto, la distribución de contenidos entre los diferentes sectores del ordenamiento no puede llevarse a cabo recurriendo únicamente al concepto de bien jurídico, sino que es necesario acudir a otros principios o juicios que aludan tanto a criterios de carácter axiológico como de carácter utilitaris-

${ }^{1}$ B. J. FeIjoo SáncheZ, «Sobre la crisis del bien jurídico...», op. cit., y A. von Hirsch, «El concepto de bien jurídico...», op. cit., p. 52.

92 Aunque muchos autores se lo han atribuido a Roxin dado que este autor siempre ha defendido la idea de que el bien jurídico es «una directriz político-criminal del legislador». Vid. C. Roxin, «¿Es la protección de bienes jurídicos una finalidad del Derecho penal?», en R. HeFEndeHL (ed.), La teoría del bien jurídico. ¿Fundamento de legitimación del Derecho penal o juego de abalorios dogmático?, Barcelona-Madrid, Marcial Pons, 2007, 452.

93 En igual sentido vid. R. AlCÁCER Guirao, ¿Lesión de bien jurídico..., op. cit., p. 24, y J. M. Silva SÁnchez, Aproximación al Derecho penal..., op. cit., p. 267. Los principios de intervención mínima (fragmentariedad y subsidiariedad) que se construyen sobre el bien jurídico aportarán más información sobre si nos encontramos ante una intervención legítima. Vid. M. Corcoy BidASOLO, «Expansión del Derecho penal...», op. cit.

${ }^{94}$ C. Roxin, «El concepto de bien jurídico...», op. cit.

${ }^{2}$ Así, J. M. Silva SÁnchez, Aproximación al Derecho penal..., op. cit., p. 276; O. García Pérez, La punibilidad en el Derecho penal, Cizur Menor, Aranzadi, 1997, p. 332, y C. Roxin, Strafrecht..., op. cit., p. 32. 
ta ${ }^{96}$. Como dicen Wohlers y Hirsch, prácticamente hoy día toda conducta penal puede vincularse a un objeto de protección legítimo, por lo que más importante que la existencia de un objeto digno de protección penal será averiguar hasta qué punto y qué conductas pueden legítimamente integrarse en el Derecho penal ${ }^{97}$.

Así, los principios de fragmentariedad y subsidiariedad juegan un papel crítico mayor que el bien jurídico, pero se construyen irremediablemente sobre el mismo ${ }^{98}$, especialmente el de fragmentariedad, que analiza la importancia del objeto de tutela y las conductas que más gravemente lo afectan ${ }^{99}$. El principio de fragmentariedad se asienta sobre la idea de que el Derecho penal debe quedar reservado para prevenir conductas gravemente perjudiciales, por lo que analiza si el bien jurídico es suficientemente importante y si los ataques contemplados por tipo son suficientemente graves como para merecer un reproche penal ${ }^{100}$. Por su parte, el de subsidiariedad o ultima ratio se asienta sobre la idea de que el Derecho penal sólo debe intervenir cuando fracasen o no esten disponibles otros medios de solución social del conflicto, por lo que trata de agotar los medios de control social menos lesivos disponibles tanto fuera como dentro del ordenamiento jurídico antes de recurrir a la ultima ratio ${ }^{101}$.

En realidad, el bien jurídico y los juicios de fragmentariedad y subsidiariedad son ordenados racionalmente junto al resto de los principios y valores que han de inspirar el Derecho penal de un Estado social y democrático de Derecho, tarea que algunos autores llevan a cabo a través del principio de proporcionalidad y otros, a través de una teoría de la legislación ${ }^{102}$. Una de las teorías legislativas que mejor ha ordenado y sistematiza-

96 R. Alcácer Guirao, ¿Lesión de bien jurídico..., op. cit., p. 24.

97 A. von Hirsch y W. Wohlers, «Teoría del bien jurídico...», op. cit., p. 287.

98 C. Roxin, «El concepto de bien jurídico...», op. cit.; J. L. DíEz RIPOLlés, «La contextualización del bien jurídico...», op. cit., p. 35; S. SOTO NAVARRO, La protección penal de los bienes..., op. cit., p. 82; A. M. PRIETO DEL PINO, El Derecho penal ante el uso..., op. cit., p. 211, y P. LAURENZo Copello, «Recensión a J. M. Silva Sánchez...», op. cit., p. 449.

${ }_{99}$ Aluden a la idea de que el juicio de fragmentariedad se construye sobre el bien jurídico S. Mir Puig, El Derecho penal en el Estado social y democrático de Derecho, Barcelona, Ariel, 1994, p. 166, y A. M. Prieto Del Pino, El Derecho penal ante el uso..., op. cit., p. 211.

100 J. L. Díez Ripollés, La racionalidad..., op. cit., pp. 140-141; J. M. Silva SÁnchez, Aproximación al Derecho penal..., op. cit., p. 267; C. RoxIn, Strafrecht..., op. cit., p. 45; S. MIR Puig, El Derecho penal..., op. cit., p. 218, y O. GARCíA PérEz, La punibilidad en el Derecho..., op. cit., pp. 332- 333.

${ }^{101}$ C. Roxin, Strafrecht..., op. cit., p. 45; J. L. Díez Ripollés, Derecho penal español.., op. cit., p. 23; J. M. SILVA SÁncheZ, Aproximación al Derecho penal..., op. cit., p. 247, y S. MIR Puig, Introducción a las bases..., op. cit., p. 125.

${ }_{102}$ Aluden expresamente a la necesidad de una teoría de la legislación W. HASSEMER, 
do esos principios y valores en los que prácticamente toda la doctrina coincide que han de orientar la intervención penal es la teoría de la legislación racional que propone Díez Ripollés ${ }^{103}$. Basada en la teoría de la legislación de Atienza, el autor analiza la intervención penal a través de diversos niveles de racionalidad. El aspecto diferencial de la misma con respecto a otras es precisamente que no se limita a trasponer sin más los principios que rigen en la aplicación del Derecho al ámbito de la legislación, sino que incorpora además otro tipo de análisis relacionados con las ideas de eficacia, eficiencia y efectividad ${ }^{104}$.

\section{CONCLUSIÓN}

La supuesta crisis del bien jurídico que cuestiona si nos encontramos ante un instrumento capaz de limitar las intervenciones del ius puniendi obedece en algunos casos a concepciones doctrinales que, de una forma $u$ otra, lo configuran como un instrumento inútil, formal o dependiente del legislador; en otros, a que la dañosidad social de las conductas trasladadas o de su importancia para la convivencia social externa carece de una base empírico-social que la sustente, y en otras, a exageradas expectativas suscitadas por este elemento como instrumento de contención penal que lo elevan a la categoría de guía para el legislador ${ }^{105}$. Sin embargo, estos problemas no ponen de manifiesto la ineficacia per se de este instrumento para llevar a cabo una crítica al legislador, sino la existencia de ciertas concepciones que lo vacían de contenido y le impiden llevar a cabo dicha tarea.

Ahora bien, como se ha puesto de manifiesto, el bien jurídico tiene una capacidad crítica limitada en la medida que necesita ser complementado de otros juicios y principios de la intervención penal, debiendo ser incorporado al principio de proporcionalidad o a una teoría de la legislación.

«¿Puede haber delitos que no afecten...», op. cit., p. 100, y J. L. Díez RiPollés, La racionalidad..., op. cit., pp. 205-206. Sin embargo, otros autores acuden al principio de proporcionalidad para llevar a cabo dicha tarea. Vid. W. HASSEMER, «¿Puede haber delitos que no afecten...», op. cit., p. 97; J. M. SILVA SÁNCHEZ, Aproximación al Derecho penal..., op. cit., p. 267; S. Mir Puig, «Límites del normativismo...», op. cit., y J. A. Lascuraín SÁnCHeZ y M. RuscoNI (dirs.), El principio de proporcionalidad..., op. cit.

${ }_{103}$ Vid. J. L. Díez RIPollés, La racionalidad..., op. cit.

${ }_{104}$ Ibid., p. 106. El autor pone de manifiesto la relación entre los principios que han de regir la intervención penal (niveles de racionalidad legislativa) y los criterios de interpretación de las leyes que no tienen por qué identificarse.

${ }^{105}$ Así, tal y como afirma Seher, al bien jurídico se le están exigiendo expectativas que simplemente lo superan. Vid. G. SEHER, «La legitimación de normas penales...», op. cit., p. 70. 
Por tanto, que el legislador proteja un bien jurídico legítimo no significa que esa criminalización lo sea. Para poder afirmar que una intervención del legislador es legítima hay que llevar a cabo una serie de juicios posteriores, pero que se construyen irremediablemente sobre el mismo. Por tanto, tal y como afirman los denominados «detractores» de su función de contención del ius puniendi, el debate penal actual en torno a los límites del Derecho penal será más fructífero a la hora de eliminar determinados contenidos en la medida que sea capaz de incorporar argumentos al margen del concepto de bien jurídico ${ }^{106}$.

\section{BIBLIOGRAFÍA}

Abanto Vásquez, M. A., «Acerca de la teoría de bienes jurídicos», Revista Penal, núm. 18 (2006), pp. 3-44.

AlCÁCer GUIRAO, R., ¿Lesión de bien jurídico o lesión de deber? Apuntes sobre el concepto material del delito, Barcelona, Atelier, 2003.

Alonso Álamo, M., «Bien jurídico material y bien jurídico procedimental y discursivo», en J. C. Carbonell Mateu, J. L. González Cussac y E. Orts Berenguer (dirs.), y M. L. Cuerda Arnau (coord.), Constitución, derechos fundamentales y sistema penal (semblanzas y estudios con motivo del setenta aniversario del profesor Tomás Salvador Vives Antón), vol. I, Valencia, Tirant lo Blanch, 2009.

Amelung, K., Rechtsgüterschutz und Schutz der Gesellschaft, Frankfurt am Main, Athenäum, 1972.

— «El concepto "bien jurídico" en la teoría de la protección penal de bienes jurídicos», en R. HeFendehl (ed.), La teoría del bien jurídico. ¿Fundamento de legitimación del Derecho penal o juego de abalorios dogmático?, Barcelona-Madrid, Marcial Pons, 2007, pp. 227-264.

Asúa BAtARRitA, A., «La tutela penal del correcto funcionamiento de la Administración. Cuestiones político-criminales, criterios de interpretación y delimitación respecto a la potestad disciplinaria», en A. Asúa Batarrita (ed.), Aspectos generales de los delitos contra la Administración pública, Vitoria-Gasteiz, Gobierno Vasco-Instituto Vasco de Administración Pública, 1997, pp. 13-55.

BACIgALUPO ZAPATER, E., «Sobre la reforma de los delitos de los funcionarios», Documentación jurídica, núm. 37/40, vol. 2 (1983), pp. 1095-1105.

Bustos Ramírez, J., Control social y sistema penal, Barcelona, PPU, 1987.

- Manual de Derecho Penal. Parte General, corregida por H. Hormazábal Malarée, Barcelona, PPU, 1994.

106 W. Frisch, «Bien jurídico, derecho...», op. cit., p. 319, y B. J. FeIJOO SÁnChEZ, «Sobre la crisis del bien jurídico...», op. cit. 
Corcoy Bidasolo, M., «Expansión del Derecho penal y garantías constitucionales», Revista de Derechos Fundamentales, núm. 8 (2012), pp. 46-76.

De la Mata Barranco, N. J., «¿Qué interés lesionan las conductas de corrupción?», Eguzkilore, núm. 23 (2009), pp. 245-259.

Díez Ripollés, J. L., «La contextualización del bien jurídico protegido», en J. L. Díez RIPollés, Estudios penales y de política criminal, Lima, Idemsa, 2007.

- La racionalidad de las leyes penales, Madrid, Trotta, 2013.

- Derecho penal español. Parte general en esquemas, 4. ${ }^{a}$ ed., Valencia, Tirant lo Blanch, 2016.

Feijoo SÁnchez, B. J., «Delitos contra la Administración Pública: consideraciones generales, nuevas figuras delictivas y modificación de otras conocidas», La Ley, núm. 2 (1997), pp. 1678-1694.

— «Sobre la crisis del bien jurídico. Recensión a R. Hefendehl (ed.): La teoría del bien jurídico. ¿Fundamento de legitimación del Derecho penal o juego de abalorios dogmático?», Indret. Revista para el análisis del Derecho, núm. 2 (2008).

Ferré Olivé, J. C., «Corrupción y delitos contra la Administración Pública», en J. C. Ferré Olivé (dir.), Delitos financieros, fraude y corrupción en Europa, vol. III, Salamanca, Universidad de Salamanca, 2002, pp. 13-26.

FRISCH, W., «Bien jurídico, derecho, estructura del delito e imputación en el contexto de la legitimación de la pena estatal», en R. HEFENDEHL (coord.), La teoría del bien jurídico. ¿Fundamento de legitimación del Derecho penal o juego de abalorios dogmático?, Barcelona-Madrid, Marcial Pons, 2007, pp. 309-340.

GARCÍA ArÁn, M., «La prevaricación administrativa y otros comportamientos injustos en el Código Penal de 1995», Revista Aragonesa de Administración Pública, núm. 11 (1997), pp. 357-370.

García Pérez, O., La punibilidad en el Derecho penal, Cizur Menor, Aranzadi, 1997.

Gimbernat Ordeig, E., en R. Alcácer Guirao, ¿Lesión de bien jurídico o lesión de deber? Apuntes sobre el concepto material del delito, Barcelona, Atelier, 2003.

Hassemer, W., «¿Puede haber delitos que no afecten a un bien jurídico penal?», en R. HEFENDEHL (coord.), La teoría del bien jurídico. ¿Fundamento de legitimación del Derecho penal o juego de abalorios dogmático?, Barcelona-Madrid, Marcial Pons, 2007, pp. 95-104.

HefendeHL, R., Kollektive Rechtsgüter im Strafrecht, Köln-Berlin-Bonn-München, Carl Heymanns, 2002.

- «El bien jurídico como eje material de la norma penal», en R. HeFENDEHL (coord.), La teoría del bien jurídico. ¿Fundamento de legitimación del Derecho penal o juego de abalorios dogmático?, Barcelona-Madrid, Marcial Pons, 2007, pp. 179-196.

- «Las jornadas desde la perspectiva de un partidario del bien jurídico», en R. HEFENDEHL (coord.), La teoría del bien jurídico. ¿Fundamento de legitimación del Derecho penal o juego de abalorios dogmático?, Barcelona-Madrid, Marcial Pons, 2007, p. 409-416. 
Hörnle, T., «La protección de sentimientos en el STGB», en R. HeFEndeHL (coord.), La teoría del bien jurídico. ¿Fundamento de legitimación del Derecho penal o juego de abalorios dogmático?, Barcelona-Madrid, Marcial Pons, 2007, pp. 383-402.

Jakobs, G., Strafrecht Allgemeiner Teil. Die Grundlagen und die Zurechnungslebre, 2. ${ }^{a}$ ed., Berlin, De Gruyter, 1993.

- «¿Qué protege el Derecho penal: bienes jurídicos o la vigencia de la norma?», Cuadernos de doctrina y jurisprudencia penal, vol. VII, núm. 11 (2001), pp. $23-42$.

Jescheck, H. H., Tratado de Derecho penal: parte general, traducción y adiciones de S. Mir Puig y F. Muñoz Conde, Barcelona, Bosch, 1981.

KAHLO, M., «Sobre la relación entre el concepto de bien jurídico y la imputación objetiva en Derecho penal», en R. HEFENDEHL (coord.), La teoría del bien jurídico. ¿Fundamento de legitimación del Derecho penal o juego de abalorios dogmático?, Barcelona-Madrid, Marcial Pons, 2007, pp. 53-68.

KindHÄuser, U., Strafrecht Allgemeiner Teil, 6. a ed, Berlin, Nomos, 2013.

KuHLEN, L., «Der Handlungserfolg der strafbaren Gewässerverunreinigung $(\$ 324) »$, Goltdammer's Archiv für Strafrecht, Heidelberg, Decker, 1986, pp. 389-408.

Lascuraín, J. A., «Bien jurídico y objeto protegible», Anuario de Derecho penal y ciencias penales, t. 60, núm. 1 (2007), pp. 119-163.

Lascuraín SÁnchez, J. A., y Rusconi, M. A. (dirs.), El principio de proporcionalidad penal, Buenos Aires, Ad hoc, 2014.

Laurenzo Copello, P. R., «Recensión a J. M. Silva Sánchez, La expansión del Derecho penal. Aspectos de la politica criminal en las sociedades postindustriales, 2." ed., Madrid, Civitas, 2001», Revista de Derecho penal y criminología, 2. época, núm. 12 (2003), pp. 441-456.

Loos, F., «El bien jurídico en los delitos de cohecho», en K. Ambos y H. RadKE (coords.), Estudios filosófico-jurídicos y penales del profesor Fritz Loos. Homenaje a sus setenta años, Chile, Editorial Jurídica de Chile, 2009, pp. 143-162.

Martín PARDo, A., El bien jurídico protegido en los delitos urbanísticos, tesis doctoral, Málaga, Facultad de Derecho de la Universidad de Málaga, 2015.

Mir Puig, S., Introducción a las bases del Derecho penal, Barcelona, Bosch, 1976.

— «Bien jurídico y bien jurídico-penal como límites del ius puniendi», Estudios penales y criminológicos, núm. 14 (1989-1990), pp. 203-216.

- El Derecho penal en el Estado social y democrático de Derecho, Barcelona, Ariel, 1994.

- «Límites del normativismo en Derecho penal», Revista electrónica de ciencia penal y criminología, núm. 7-18 (2005), disponible en bttp://criminet.ugr.es/ recpc/07/recpc07-18.pdf.

Olaizola Nogales, I., El delito de cohecho, Valencia, Tirant lo Blanch, 1998.

Ortiz de Urbina Gimeno, I., La excusa del positivismo. La presunta superación del «positivismo»y el «formalismo»por la dogmática penal contemporánea, Madrid, Civitas, 2007, pp. 62-63. 
Peñaranda Ramos, E., «Sobre la influencia del funcionalismo y la teoría de los sistemas en las actuales concepciones de la pena y del concepto de delito», Doxa. Cuadernos de Filosofía del Derecho, núm. 23 (2003), pp. 289-321.

Prieto del Pino, A. M., El Derecho penal ante el uso de información privilegiada en el mercado de valores, Cizur Menor, Thomson Aranzadi, 2004.

Robinson, P. H., Principios distributivos del Derecho penal. A quién debe sancionarse y en qué medida, Madrid-Barcelona-Buenos Aires, Marcial Pons, 2012.

Robles Planas, R., «Introducción a la edición española. Dogmática de los límites al Derecho penal», en R. Robles Planas (ed.), Limites al Derecho penal. Principios operativos en la fundamentación del castigo, Barcelona, Atelier, 2012, pp. 19-48.

Rodríguez Montañés, T., Delitos de peligro, dolo e imprudencia, Madrid, Centro de Estudios Judiciales, 1994.

Rodríguez Puerta, M. J., El delito de cohecho: problemática jurídico-penal del soborno de funcionarios, Madrid, Aranzadi, 1999

Roxin, C., Strafrecht. Allgemeiner Teil, Band. 1, 4. ${ }^{a}$ ed., München, C. H. Beck, 2006.

- «¿Es la protección de bienes jurídicos una finalidad del Derecho penal?», en R. HeFEndeHL (coord.), La teoría del bien jurídico. ¿Fundamento de legitimación del Derecho penal o juego de abalorios dogmático?, Barcelona-Madrid, Marcial Pons, 2007, pp. 443-458.

- «El concepto de bien jurídico como instrumento de crítica legislativa sometido a examen», Revista electrónica de ciencia penal y criminología, núm. 15 (2013).

SEHER, G., «La legitimación de normas penales basada en principios y el concepto de bien jurídico», en R. HEFENDEHL (coord.), La teoría del bien jurídico. ¿Fundamento de legitimación del Derecho penal o juego de abalorios dogmático?, Barcelona-Madrid, Marcial Pons, 2007, pp. 69-94.

Schünemann, B., «Moderne Tendenzen in der Dogmatik der Farhlässigkeits- und Gefährdungs-delikte», JA (1975), pp. 435-798, esp. p. 798.

- «El principio de protección de bienes jurídicos como punto de fuga de los límites constitucionales de los tipos penales y de su interpretación», en R. HEFENDE$\mathrm{HL}$ (coord.), La teoría del bien jurídico. ¿Fundamento de legitimación del Derecho penal o juego de abalorios dogmático?, Barcelona-Madrid, Marcial Pons, 2007, pp. 197-226.

Silva Sánchez, J. M., Aproximación al Derecho penal contemporáneo, Barcelona, Bosch, 1992.

- La expansión del Derecho penal. Aspectos de la política criminal en las sociedades postindustriales, 2. " ed, Madrid, Civitas, 2001.

Soto Navarro, S., La protección penal de los bienes colectivos en la sociedad moderna, Granada, Comares, 2003.

Stratenwerth, G., «La criminalización en los delitos contra bienes jurídicos colectivos», en R. HEFENDEHL (coord.), La teoría del bien jurídico. ¿Fundamento de legitimación del Derecho penal o juego de abalorios dogmático?, BarcelonaMadrid, Marcial Pons, 2007, pp. 365-372. 
Terradillos Basoco, J., «La satisfacción de necesidades como criterio de determinación del objeto de tutela jurídico-penal», Revista de la Facultad de Derecho de la Universidad Complutense, núm. 63 (1981), pp. 124-149.

Valeije Álvarez, I., El tratamiento penal de la corrupción del funcionario: el delito de cobecho, Madrid, Editoriales de Derecho Reunidas, 1995.

Von Hirsch, A., «El concepto de bien jurídico y el "principio del daño"», en R. HEFENDEHL (coord.), La teoría del bien jurídico. ¿Fundamento de legitimación del Derecho penal o juego de abalorios dogmático?, Barcelona-Madrid, Marcial Pons, 2007, pp. 37-52.

Von Hirsch, A., y Wohlers, W., «Teoría del bien jurídico y estructura del delito. Sobre los criterios de una imputación justa», en R. HEFENDEHL (coord.), La teoría del bien jurídico. ¿Fundamento de legitimación del Derecho penal o juego de abalorios dogmático?, Barcelona-Madrid, Marcial Pons, 2007, pp. 285-308. 
